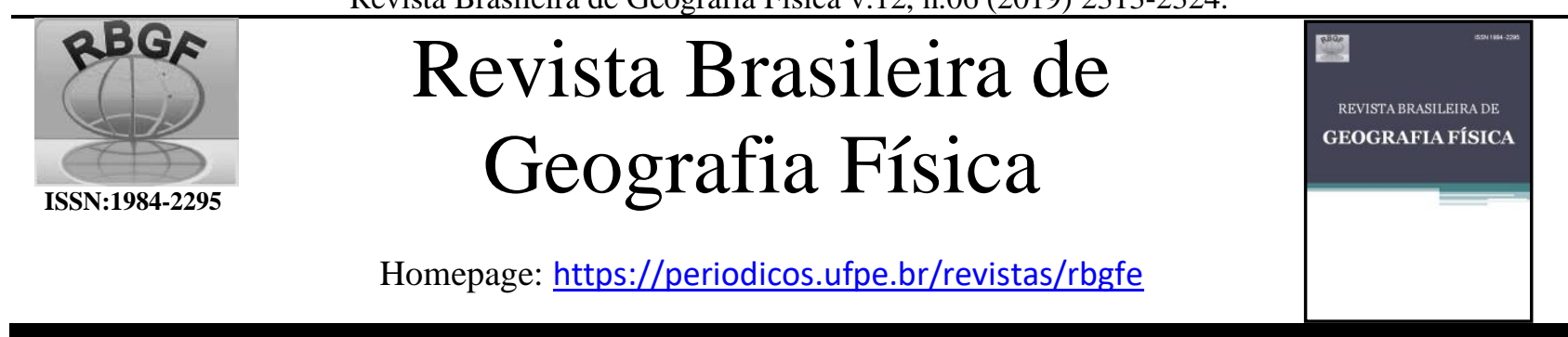

\title{
Distribuição espaço-temporal do conforto térmico na malha cicloviária em Recife-PE
}

\author{
Rafael Silva dos Anjos 1, Ayobami Badiru Moreira 2, Tamires Gabryele de Lima Mendes ${ }^{3}$,Tanelly Neriah \\ Santos ${ }^{4}$ Cleusa Aparecida Gonçalves Pereira Zamparoni ${ }^{5}$ e Ranyére Silva Nóbrega ${ }^{6}$
}

\begin{abstract}
1 Doutorando em Geografia, Universidade Federal de Pernambuco, Av. Prof. Moraes Rego, 1235, Cidade Universitária Recife - PE anjos.rsa@gmail.com (autor correspondente). ${ }^{2}$ Doutoranda em Geografia, Universidade Federal de Pernambuco, Av. Prof. Moraes Rego, 1235, Cidade Universitária Recife - PE.ayo.badiru@ hotmail.com. ${ }^{3}$ Mestranda em Geografia, Universidade Federal de Pernambuco.tamires25lima@hotmail.com. ${ }^{4}$ Mestranda em Geografia, Universidade Federal de Pernambuco tanelly_neriah@hotmail. ${ }^{5}$ Doutora em Geografia, Universidade Federal de Pernambuco. cazamp@gmail.com .6 Prof. Dr. do Programa de Pós-graduação em Geografia da Universidade Federal de Pernambuco. ranyere.nobrega@ufpe.br.
\end{abstract}

Artigo recebido em 21/05/2019 e aceito em 24/01/2020

\section{R E S U M O}

O ciclismo é uma das práticas desportivas que mais vem crescendo nos espaços urbanos. Por ser praticada ao ar livre, na maioria dos casos, as condições do ambiente podem influenciar no condicionamento físico dos ciclistas, de acordo com o seu conforto térmico. Por isso, a proposta dessa pesquisa foi avaliar as condições de conforto térmico em toda a malha cicloviária em Recife, município situado no nordeste do Brasil. Para isso, foi necessário interpolar as médias mensais de umidade e temperatura do ar, nos horários de 6:00, 12:00 e 18:00, para posteriormente calcular a Temperatura Efetiva e produzir cartograficamente sua distribuição espacial. Foi identificado que o conforto térmico nas ciclofaixas estão relacionadas à hora, mês e localização geográfica das vias. Os resultados permitiram apontar que a sensação de calor leve nas ciclofaixas e ciclovias predominaram ao longo da série histórica. No entanto, outubro de 2015, às 6:00, apresentou sensações confortáveis em toda a malha cicloviária, enquanto janeiro de 2016 às 12:00 apresentou condições mais adversas para o ciclismo. Diante dos resultados analisados, propõe-se um planejamento urbano que leve em consideração o conforto térmico dos ciclistas assim como ações que promovam os cuidados necessários para os ciclistas em condições térmicas adversas, de acordo com o período e a área da prática do ciclismo.

Palavras-chave: conforto térmico, ciclovia, temperatura efetiva.

\section{Spatial-temporal distribution of cycling in Recife-PE}

\begin{abstract}
A B S T R A C T
Cycling is one of the sporting practices that is growing the most in urban spaces. Because it is practiced outdoors, in most cases, the conditions of the environment can influence the physical conditioning of cyclists, according to their thermal comfort. Therefore, the proposal of this research was to evaluate the thermal comfort conditions in the entire cycle network in Recife, a municipality located in northeastern Brazil. For this, it was necessary to interpolate the monthly averages of humidity and air temperature, at the times of 6:00, 12:00 and 18:00, to later calculate the Effective Temperature and produce cartographically its spatial distribution. It was identified that the thermal comfort in the cycle ranges are related to the time, month and geographical location of the tracks. The results allowed to point out that the sensation of light heat in the cycle ranges and cycle paths predominated throughout the historical series. However, October of 2015, at 6:00 am, presented comfortable sensations throughout the cycling network, while January of 2016 at 12:00 showed more adverse conditions for cycling. Considering the results analyzed, it is proposed an urban planning that takes into account the thermal comfort of cyclists as well as actions that promote the necessary care for cyclists in adverse thermal conditions, according to the period and the area of cycling practice.
\end{abstract}

Keywords: thermal comfort, cycle path, effective temperature.

\section{Introdução}

Ao longo de sua história, o conceito de esporte foi sendo debatido de maneira que as transformações políticas e sociais refletissem em sua transformação no decorrer dos anos. Desde a 
Revista Brasileira de Geografia Física v.12, n.06 (2019) 2313-2324.

definição de desporto como um simples divertimento, no Diccionário de língua portugueza no começo do século XIX, até os dias de hoje, a prática desportiva remete-nos a algo mais complexo, já que atualmente o termo pode nos sugerir tanto modo de competição, como práticas de atividades físicas e ações que promovam à saúde do atleta (Melo, 2010).

Não menos complexo, são as motivações para a prática de esportes que podem ir desde a uma busca por uma vida mais saudável, ou até engajamentos em práticas sustentáveis. Essa complexidade é pertinente para a classificação das variantes de atividades desportivas, as quais incluem as práticas corporais em meio natural. Como proposta para definição, os franceses classificaram as atividades físicas em meio natural no fim do século XIX como "Plein air" (Melo,2009).

É válido salientar que essas práticas esportivas tiveram incentivos por meio de órgãos governamentais nos Estados Unidos e Canadá com o reconhecimento das atividades físicas como caminhada, ciclismo, natação como cruciais para a saúde humana. Essa valorização de práticas esportivas ao ar livre aumentou ao longo do tempo. Para exemplificar, na França em 1967, 39\% dos cidadãos com 14 anos ou mais praticavam algum tipo de esporte, já em 2000, esse número passou para $83 \%$. Atualmente, a popularização de práticas desportivas ao ar livre, como o ciclismo, vem se popularizando. Na França, por exemplo, estima-se que existam mais de 10 milhões de praticantes (Inserm, 2008).

Por trás da popularização do ciclismo, existe uma trajetória de aperfeiçoamento da bicicleta até os moldes que conhecemos atualmente. Mesmo que possamos considerar seus primórdios desde o século XIII, a criação da bicicleta moderna com um formato próximo do atual foi em 1863, tendo como inventores os irmãos Pierre e Ernest Michaud. não demorou muito para que no fim do século XIX, o ciclismo - como esporte - fosse popularizado na França, com a criação de provas de estradas, sendo adotadas por todas as camadas sociais (Melo e Schetino, 2009).

Por ter baixo custo, promover vantagens para o meio ambiente e estimular a atividade física, o ciclismo vem aumentando cada vez mais no Brasil. O resultado disso está no fato do Brasil possuir a sexta maior frota de bicicletas no mundo, sendo o transporte individual mais utilizado no país. As previsões acerca do seu uso no futuro, sugere um aumento considerável, já que com criações de iniciativas públicas e privadas estimulam os governos municipais e estaduais a desenvolver ações que favoreçam a utilização da bicicleta de modo mais seguro (Garcia et al., 2013).

Como grande parte dos eventos esportivos, dentre eles o ciclismo, é realizado ao ar livre, os mesmos estão sujeitos à atrasos e cancelamentos, devido as condições do tempo atmosférico. Além disso, alguns fatores podem comprometer o desempenho do ciclista, sendo estes por fatores do indivíduo e/ou do ambiente que está sendo praticado o ciclismo.

Dentre os elementos climáticos que mais influenciam no vigor físico do homem são a temperatura, umidade e vento. Para exemplificarmos, um ar muito seco prejudica a disposição para o trabalho mental, pressões atmosféricas mais baixas resulta na diminuição de suprimento de oxigênio para o cérebro e temperaturas demasiadas altas causam a exaustão, choques e cãibras (Ayoade, 2010). Alguns estudos mostraram que os efeitos na velocidade dos ciclistas são maiores quando se alteram a temperatura do ar, pressão e umidade, respectivamente (Dwyer, 2014).

O conceito de conforto térmico pode ser caracterizado pela percepção do indivíduo de sua satisfação com as condições do ambiente térmico em que o mesmo está inserido. É válido salientar que a princípio, essa satisfação pode ser subjetiva para o sujeito, visto que as pessoas se diferenciam biológica e psicologicamente, respondendo de maneira diferenciada de acordo sob as mesmas condições atmosféricas. Apesar disso, pode-se levantar alguns fatores que contribuem para um desconforto térmico. Dentre eles, podemos citar a resistência térmica da vestimenta; temperatura do ar; velocidade do vento e; umidade relativa do ar (Deval, 1984).

Num trabalho realizado para avaliar como o conforto térmico pode influenciar no desempenho de maratonistas na cidade do Rio de Janeiro, foi identificada que, devido ao fato da prova ser longa, as sensações térmicas dos atletas iam de um leve desconforto térmico ao frio até um forte desconforto térmico ao calor. Ficou evidente que os anos que tiveram mais próximos de um conforto térmico, o tempo de corrida era menor dos ganhadores (Palotta et al., 2015).

É pertinente um planejamento urbano que leve em consideração as práticas desportivas, como o ciclismo, assim como as condições de conforto térmico que a cidade possa oferecer. A presença de estudos que busquem a identificação das variações do conforto térmico no espaço e sua relação com o ciclismo, promove ações que objetivem a prevenção de atividades onde e quando há maiores desconfortos térmicos, assim como subsidiar os 
Revista Brasileira de Geografia Física v.12, n.06 (2019) 2313-2324.

gestores municipais a mitigar os efeitos das ilhas de calor onde as ciclofaixas estão presentes.

Recife possui uma configuração espacial de conforto térmico diversificado, diferenciando-se de acordo com os tipos de ocupação urbana e suas características ambientais. Nesse sentido, alguns trabalhos acadêmicos levantam unidades que possuem características socioambientais em Recife que influenciam na distribuição espacial da temperatura (Barros e Lombardo, 2012).

É válido salientar que os trechos das ciclofaixas existentes no município podem ser diferenciadas no que diz respeito às zonas de confortos térmicos que os mesmos atravessam. Por isso, deve-se levar em consideração um planejamento urbano que busque evitar que se retirem a vegetação. A urbanização, nesse sentido, pode contribuir para o aumento da temperatura, como acontece no centro da cidade do Recife (Nóbrega e Vital,2010)
Diante de pressuposto acima, o objetivo desse trabalho foi analisar as variações espaçotemporais da sensação térmica nas malhas cicloviárias no município de Recife, relacionandoas fenômenos antrópicos e ambientais.

\section{Material e métodos}

Área de estudo

Para o presente estudo foi selecionado o município de Recife, capital de Pernambuco, situado no Nordeste Brasileiro. Sua população está estimada em 1.625.583 habitantes no ano de 2016, a sua área territorial é de $2018 \mathrm{~km}^{2} \mathrm{e}$ sua densidade demográfica é de 7.039,64 habitantes por $\mathrm{km}^{2}$ (IBGE,2017). A malha cicloviária fixa na cidade do Recife (Erro! Fonte de referência não encontrada.) têm uma extensão de aproximadamente $36 \mathrm{~km}^{2}$ (Prefeitura do Recife, 2017).
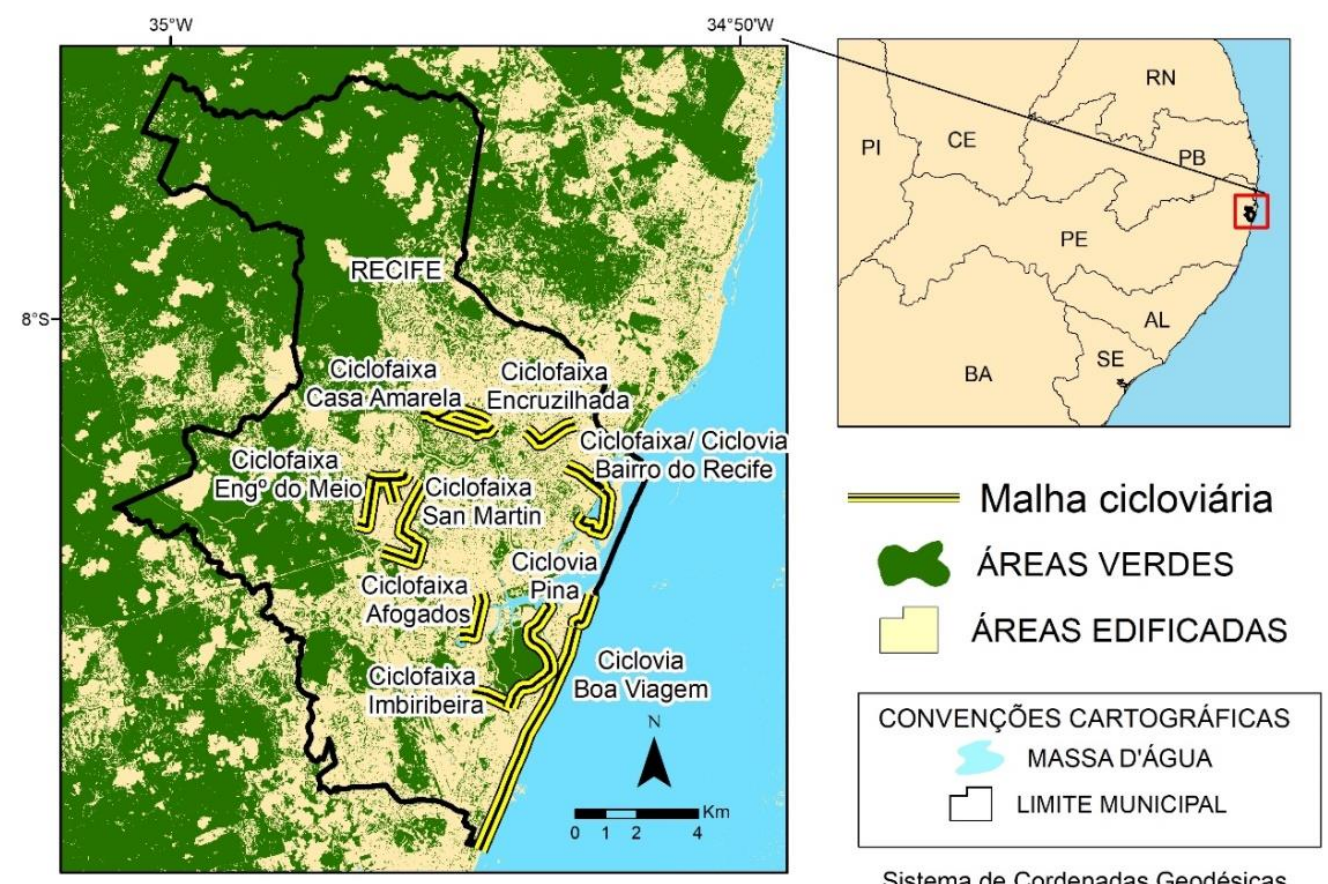

Sistema de Cordenadas Geodésicas Sistema de Referência Geodésico: SIRGAS 2000

Figura 1. Malha cicloviária nomeada de acordo com os bairros de predominância, as áreas verdes e urbanizadas em Recife-PE.

É válido ressaltar que a malha cicloviária, está alternada entre ciclofaixas e ciclovias.

A Ciclovia são vias cicláveis em que existe uma separação física entre o ciclista e os demais veículos, oferecendo maior segurança no tráfego. A ciclofaixa é uma faixa exclusiva para o tráfego de ciclistas. A presença de tachões e sinalização horizontal servem de divisão física com a pista de rolamento. Nesse caso, é menos seguro que a ciclovia (PREFEITURA DO RECIFE, 2017). A configuração espacial dessas vias cicláveis diferenciam-se de acordo com sua localização; ora próximo às áreas verdes, ora próximo aos grandes centros urbanizados, com grande concentração de edificações. Tal fato, pode indicar diferentes sensações térmicas ao longo de uma ciclofaixa, ou ciclovia.

A topografia da cidade do Recife (Erro! Fonte de referência não encontrada.) permite, 
Revista Brasileira de Geografia Física v.12, n.06 (2019) 2313-2324.

em sua maior parte, que haja um tráfego de ciclista sem grandes esforços, visto que o município se encontra dentro de uma planície litorânea com poucas variações de altitude em boa parte do território recifense. Mesmo com a presença de áreas de morros ao norte, oeste e sul do município, as malhas cicloviárias encontram-se dentro da planície.

\section{Dados utilizados}

Para a criação do índice de sensação térmica, foram utilizados dados mensais de temperatura do ar e umidade de 8 termohigrômetros, marca HOBO U20, entre outubro de 2015 e fevereiro de 2016. As médias mensais estão divididas em três horários: 6:00, 12:00 e 18:00.

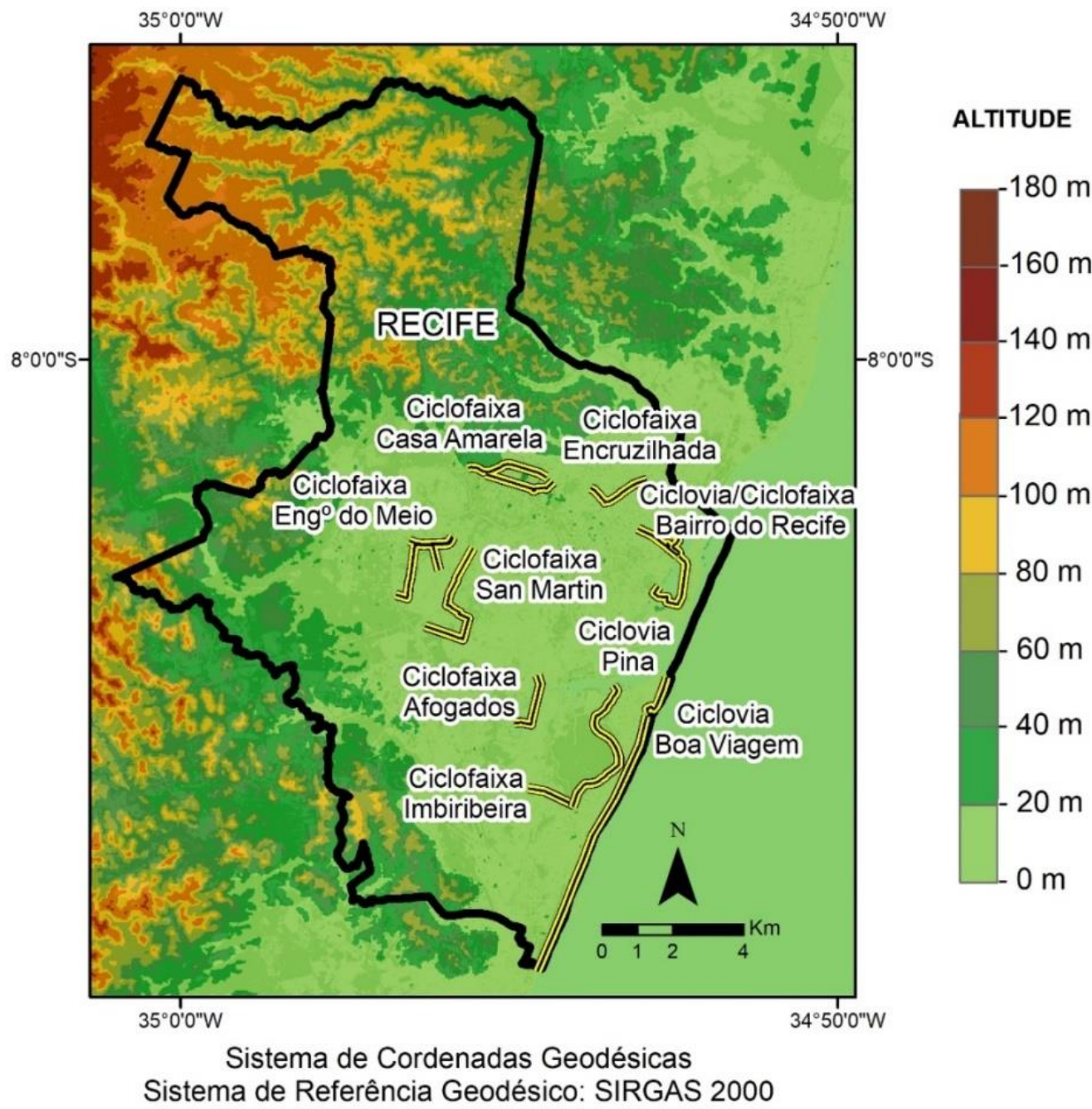

Figura 2. Hipsometria e a malha cicloviária em Recife-PE, nomeada de acordo com a predominância da sua extensão no bairro.

Esses instrumentos possuem um datalogger e abrigo para proteger da incidência direta de radiação solar e chuva. É válido salientar que o período dos dados coincide com a época menos chuvosa no litoral pernambucano, sendo propícia para a prática de esportes ao ar livre, dentre os quais, está o ciclismo.

Esses dados possuem intervalos de 30 minutos para um detalhamento diário preciso. A altitude da estação em relação ao solo foi definida em 1,5 m, considerada ideal por não sofrer forte influência do solo, fazendo com que a captação dos dados seja fiel ao ambiente circundante.

\section{Metodologia}

Foi necessário o processamento dos dados horários de temperatura e umidade dos termohigrômetros para que os mesmos apresentassem as médias mensais nos horários de 6:00, 12:00 e 18:00 de outubro de 2015 a fevereiro de 2016. Após essa organização, foi calculado o índice de sensação térmica, segundo Palotta, Herdies e Gonçalves (Equação 1): 
Revista Brasileira de Geografia Física v.12, n.06 (2019) 2313-2324.

$$
T E=T_{a}-0,4\left(T_{a}-10\right)\left(1-\frac{U R}{100}\right)
$$

Onde o TE é a Temperatura Efetiva; $\mathrm{T}_{\mathrm{a} \text { é } \mathrm{a}}$ Temperatura média do ar $\left({ }^{\circ} \mathrm{C}\right)$; e UR a Umidade relativa do ar em $(\%)$. $\mathrm{O}$ resultado pode ser comparado na (Figura 4). Calculada a Temperatura Efetiva (TE) para todas as estações

As estações foram distribuídas espacialmente de acordo com as características particulares de cada local (Figura 4), necessitando de segurança para o aparelho e de locais onde não houvessem barreiras artificiais, ou naturais, que dificultassem a coleta dos dados.

\begin{tabular}{|c|c|c|c|}
\hline Sensação Térmica & Grau de Estresse Fisiológico & Sigla & TE/TEv \\
\hline Muito Frio & Extremo estresse ao frio & EEF & $<13$ \\
\hline & & & \\
\hline Frio & Forte estresse ao frio & FEF & 13 a 16 \\
\hline & Tiritar & & \\
\hline Frio Moderado & Estresse moderado ao frio & EMF & 16 a 19 \\
\hline & Ligeiro resfriamento do corpo & & \\
\hline Ligeiramente Frio & Ligeiro estresse ao frio & LEF & 19 a 22 \\
\hline & Vasoconstrição & & \\
\hline Confortável & Nenhum estresse térmico & CFT & 22 a 25 \\
\hline & Neutralidade Térmica & & \\
\hline Ligeiramente Quente & Ligeiro estresse ao calor & LEC & 25 a 28 \\
\hline & Ligeiro Suor, vasodilatação & & \\
\hline Quente Moderado & Estresse moderado ao calor & EMC & 28 a 31 \\
\hline & Suando & & \\
\hline Quente & Forte Estresse ao calor & FEC & 31 a 34 \\
\hline & Suor em profusão, falha na termorregulação & & \\
\hline Muito Quente & Extremo estresse ao calor & EEC & $>34$ \\
\hline
\end{tabular}

Figura 3. Zona de conforto e desconforto térmico de acordo com a Temperatura Efetiva associado a percepção térmica e suas respostas fisiológicas. Fonte: Palotta, Herdies e Gonçalves.

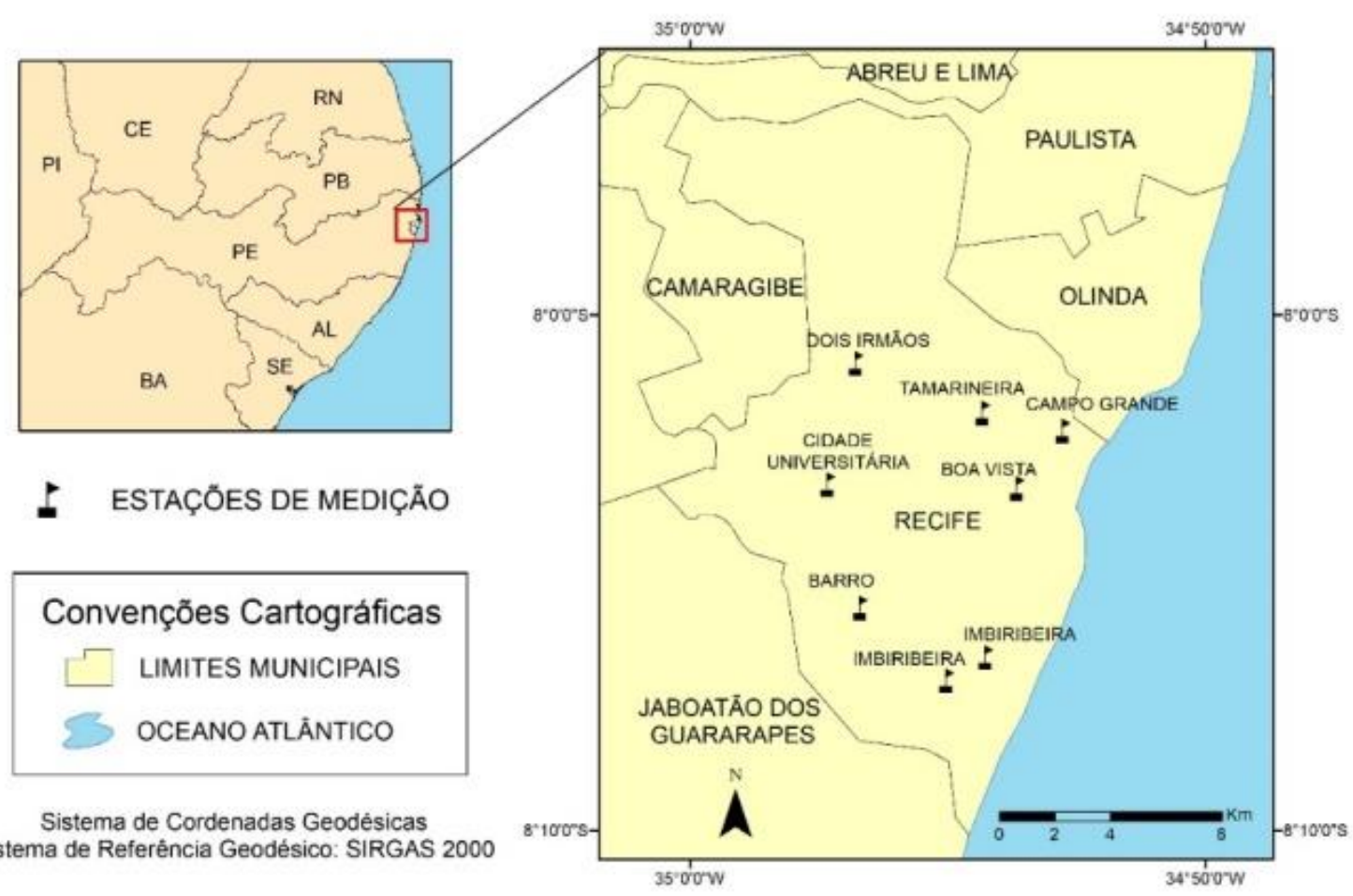

Figura 4. Distribuição espacial dos termohigrômetros e seus respectivos bairros em Recife-PE. 
Revista Brasileira de Geografia Física v.12, n.06 (2019) 2313-2324.

Os dados foram interpolados no software de processamento de dados espaciais ArcGis 10.2, bem como a elaboração cartográfica desses índices espacializados. É válido salientar que foi necessária a criação de um dado vetorial referente malha cicloviária baseado no Relatório da Malha Cicloviária existente da cidade, elaborado pela Prefeitura da Cidade do Recife.

OUTUBRO

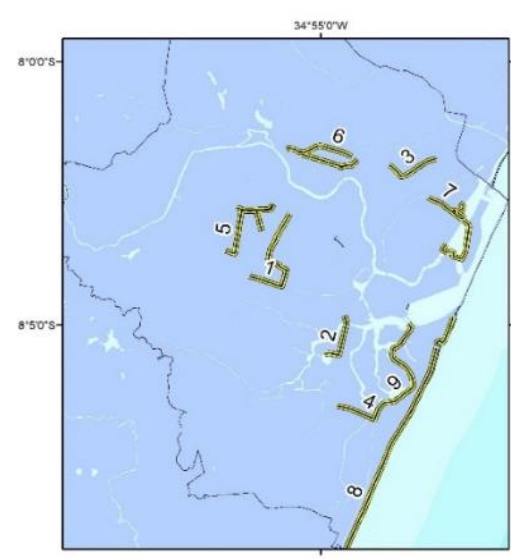

DEZEMBRO

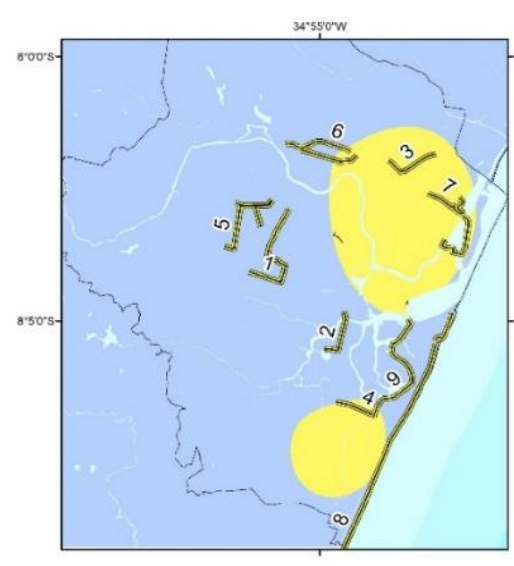

FEVEREIRO

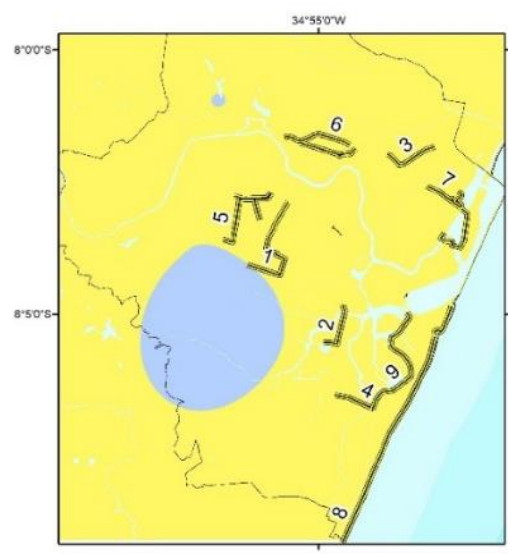

Resultados e discussão

Ao serem analisadas os dados da TE em todos horários $(6: 00,12: 00$ e 18:00) percebe-se que as mesmas tendem a variar de acordo com a sua localização geográfica e os períodos estudados. Quando verificado o mapa de distribuição da TE às 6:00 (Erro! Fonte de referência não encontrada.), é perceptível o aumento da região levemente quente, de outubro de 2015 a fevereiro de 2016.

NOVEMBRO

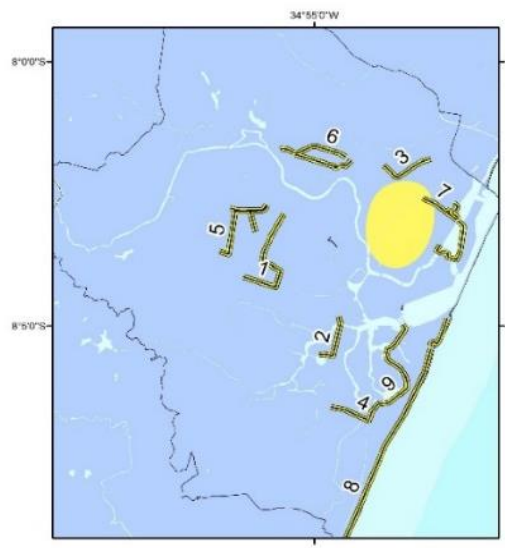

JANEIRO

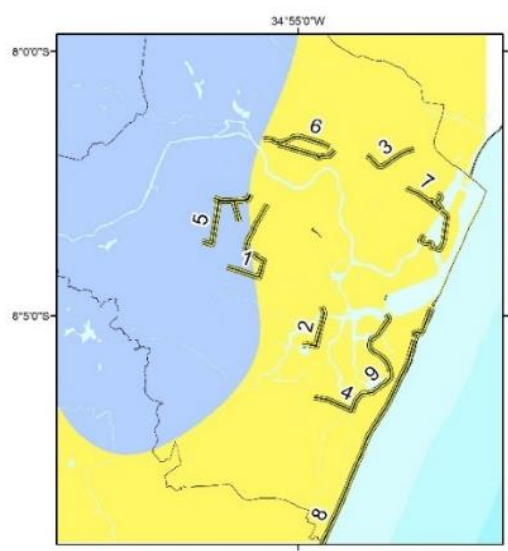

SENSAC̄ÃO TÉRMICA E GRAU DE ESTRESSE FISIOLÓGICO

23 - 25 ( Confortável - Neutralidade Térmica)

25 - 28 ( Levemente quente - Leve suor e vasodilatação)

28 - 31 (Quente moderado - Suando)

MALHA CICLOVIÁRIA

Ciclofaixa 1 - (San Martin) Ciclofaixa 2 - (Afogados) Ciclofaixa 3- (Encruzilhada) Ciclofaixa 4 - (Imbiribeira) Ciclofaixa 5 - ( Eng $^{\circ}$ do Meio) Ciclofaixa 6 - (Casa Amarela) Ciclofaixa/Ciclovia 7 - (Bairro do Recife) Ciclovia 8 - (Boa Viagem) Ciclovia 9 - (Pina)

CONVENÇŐES CARTOGRÁFICAS MASSA D'ÁGUA

LIMITE MUNICIPAL

Sistema de Cordenadas Geodésicas
Sistema de Referéncia Geodésico: SIRGAS 2000

Figura 5. Médias mensais (de outubro de 2015 a fevereiro de 2016), às 06:00, da Temperatura Efetiva associada a sensação térmica, grau de estresse fisiológico e malha cicloviária no município de Recife. 
Revista Brasileira de Geografia Física v.12, n.06 (2019) 2313-2324.

Em outubro, todas as ciclovias e ciclofaixas na cidade do Recife, apresentaram boas condições para o ciclismo, com sensações térmicas dentro da zona de conforto. Em novembro, uma pequena ilha de calor no nordeste do município já começa a atingir um setor da Ciclovia/Ciclofaixa no Bairro do Recife.

Tal fato é devido ao aumento gradativo da temperatura do ar e umidade relativa em algumas estações localizadas numa região onde há uma grande concentração de edificações que tendem a absorver mais calor. Alguns fatores podem contribuir para o aquecimento nessas áreas como: a presença de altos prédios, fachadas e telhados com tons mais escuros (favorecendo maior absorção da radiação) e poluição do ar a partir do intenso tráfego de veículos (Barros e Lombardo, 2012).

No mês de dezembro, a ilha de calor do mês anterior aumenta sua área de influência e mais uma nova se forma ao sul do município. Em relação ao mês anterior, aumentaram o número de ciclofaixas e ciclovias afetadas pela área de desconforto térmico, trazendo sensações de suor leve e vasodilatação para os ciclistas no setor leste da ciclofaixa de Casa Amarela, toda a ciclofaixa do bairro da Encruzilhada, Bairro do Recife, Imbiribeira e no setor sul da Ciclovia de Boa Viagem. No mês de janeiro de 2015, apenas a ciclofaixa do Engenho do Meio e parte da ciclofaixa de San Martin apresentaram características de conforto térmico. Em fevereiro, a área considerada levemente quente, abrangeram todas as ciclofaixas. O aumento dessa área em relação ao mês anterior, deve-se principalmente ao aumento da temperatura do ar de todas as estações de mediação.

Esse desconforto térmico pode, também, estar associado ao aumento da umidade do ar, visto que em algumas estações localizadas nessas ilhas de calor, mantiveram sua temperatura do ar ou até diminuíram em relação ao mês anterior.

A presença de vegetação nesse caso, pode ter influenciado na presença de uma área de conforto térmico no oeste recifense. Corrobora-se tal afirmativa a partir de Moreira e Galvíncio, (2009), que identificaram a presença de vegetação e corpos hídricos em Recife como condicionantesa microclimas mais agradáveis, sob o ponto de vista do conforto térmico. Quando analisadas as médias mensais da Temperatura Efetiva em Recife as 12:00 (Figura 6), a configuração espacial varia de levemente quente à quente moderado ao longo dos meses nas ciclofaixas, com maiores extensões no mês de janeiro de 2015. De outubro a novembro, não houve mudanças na sensação térmica ao longo das ciclofaixas, mostrando que nesses meses o ciclismo em toda a malha cicloviária apresentavam condições térmicas desfavoráveis para os ciclistas.

Essa configuração espacial da TE, mudou a partir de janeiro, com maiores extensões de áreas com sensação térmica de quente moderado. Destacam-se três áreas com sensações de maior calor: na porção noroeste, sul e centro de Recife. Apesar disso, essa região atingiu apenas o setor oeste da ciclofaixa do Engenho do Meio e na porção sul da ciclovia de Boa Viagem.

Em fevereiro, ao meio dia, todas as ciclovias e ciclofaixas voltam a apresentar sensações que remetem ao suor leve e vasodilatação, com a diminuição das áreas com sensação de calor moderado.

Em todo o município, essa área ficou restrita a uma pequena ilha de calor localizada no sudoeste recifense.

Essas condições adversas para o ciclismo, ressaltam a importância de estudos que identifiquem o desempenho dos ciclistas em áreas mais quentes. Nesse sentido, merecem ser destacadas algumas técnicas que promovam um estado térmico do corpo mais agradável. Alguns estudos já evidenciam que a ingestão de pequenas partículas de gelo com água líquida melhora as condições térmicas do corpo, aperfeiçoando o desempenho do ciclista em ambientes mais quentes (Schulzen et al., 2015). 
OUTUBRO

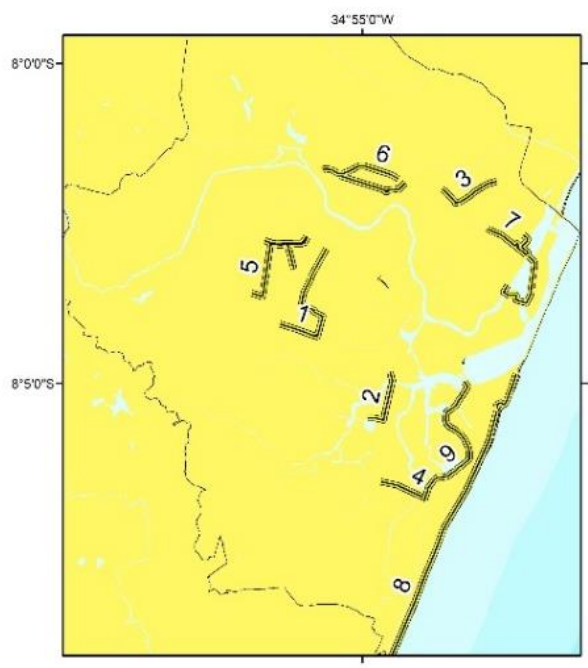

DEZEMBRO

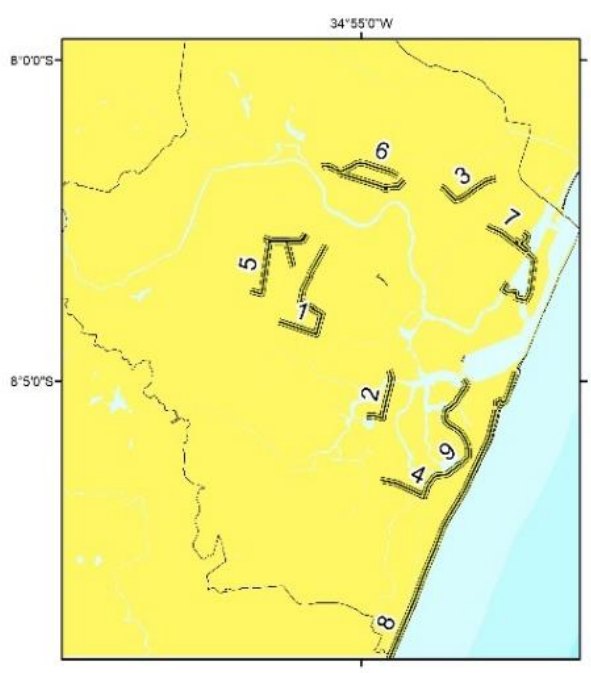

FEVEREIRO

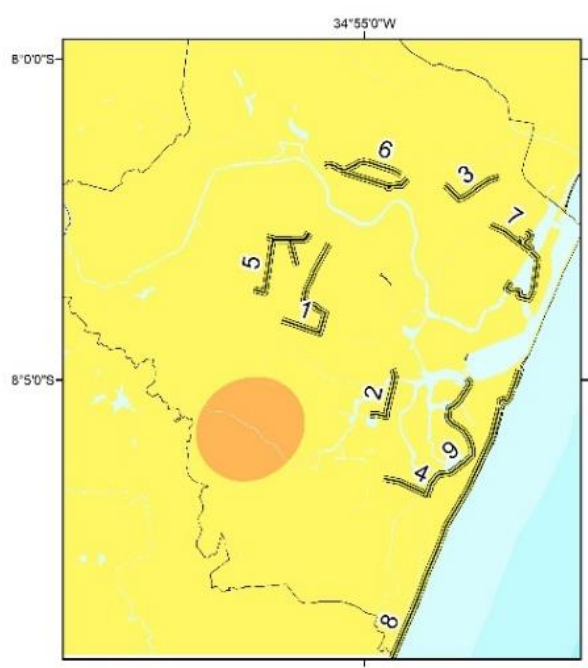

NOVEMBRO

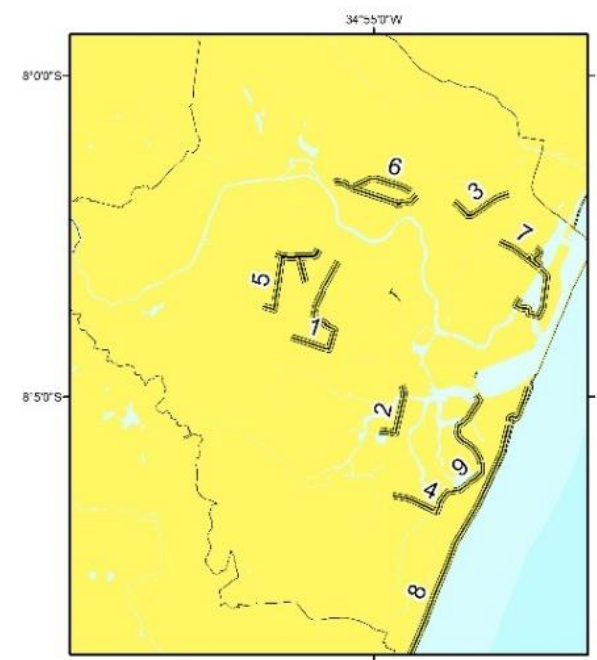

JANEIRO

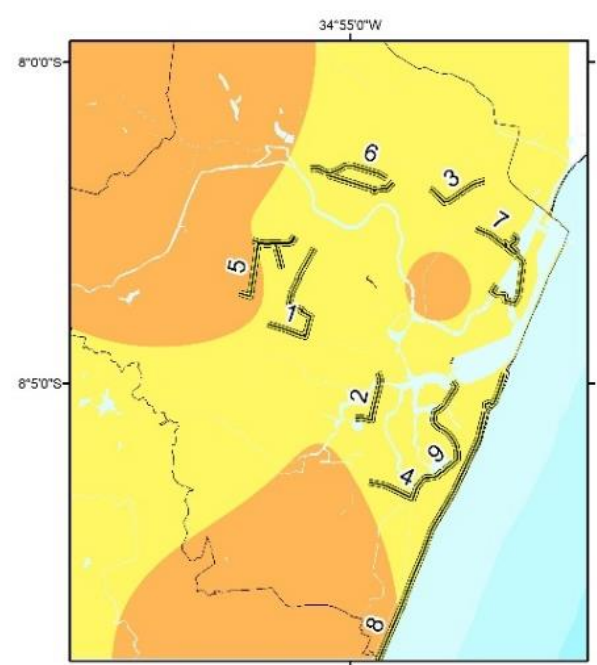

SENSAÇÃO TÉRMICA E GRAU DE ESTRESSE FISIOLÓGICO

23 - 25 ( Confortável - Neutralidade Térmica)

25 - 28 ( Levemente quente - Leve suor e vasodilatação)

28 - 31 (Quente moderado - Suando)

\section{MALHA CICLOVIÁRIA}

Ciclofaixa 1 - (San Martin)

Ciclofaixa 2 - (Afogados)

Ciclofaixa 3- (Encruzilhada)

Ciclofaixa 4 - (Imbiribeira)

Ciclofaixa 5 - ( Eng $^{\circ}$ do Meio $)$

Ciclofaixa 6 - (Casa Amarela)

Ciclofaixa/Ciclovia 7 - (Bairro do Recife)

Ciclovia 8 - (Boa Viagem)

Ciclovia 9 - (Pina)

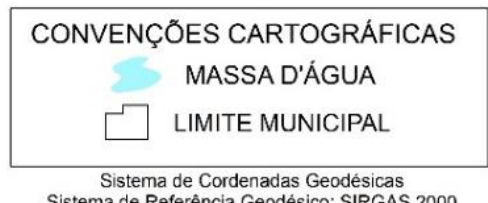

Sistema de Referência Geodésico: SIRGAS 2000

Figura 6. Médias mensais (de outubro de 2015 a fevereiro de 2016), às 12:00, da Temperatura Efetiva associada a sensação térmica, grau de estresse fisiológico e malha cicloviária no município de Recife. 
Revista Brasileira de Geografia Física v.12, n.06 (2019) 2313-2324.

Além disso, é preciso estudos que objetivem criticar as condições atuais de planejamento urbano que negligenciam uma metodologia que traga microclimas mais amenos à população, principalmente no que concerne à utilização de espaços públicos, como as ciclofaixas e ciclovias. É válido ressaltar que as diversidades paisagísticas dentro do espaço urbano já podem indicar diferentes sensações térmicas que o ciclista pode estar suscetível. Essa relação pode ser levantada com a percepção de Barros e Lombardo (2012) em que a partir de uma análise paisagística identificaram a relação entre as diferentes formas de ocupação do solo recifense com uma dinâmica espacial climática. Essa relação pode ser levantada com a percepção de Barros e Lombardo (2012) em que a partir de uma análise paisagística identificaram a relação entre as diferentes formas de ocupação do solo recifense com uma dinâmica espacial climática. Analisando as médias mensais da Temperatura Efetiva no horário das 18:00 (Erro! Fonte de referência não encontrada.), algumas particularidades mostram-se evidentes quando comparadas com os horários já apresentados.

Dentre eles, semelhanças nas condições de conforto térmico no mês de outubro com o horário das 6:00, onde todas as vias cicláveis apresentaram boas condições térmicas para o ciclismo. A única diferença entre essas duas figuras estaria numa ilha de calor ao sul às 18:00 de outubro de 2015, ainda que não tenha atingido nenhuma ciclovia.

Os meses de novembro e dezembro apresentaram sensações térmicas levemente quentes em todas ciclovias e ciclofaixas existentes em Recife às 18:00. Esse fato aproxima-se dos valores encontrados nos mesmos meses, às 12:00. Mesmo sendo num horário onde a radiação solar é baixa ou até nula em Recife, algumas das hipóteses para a manutenção do calor nesses meses seriam a absorção das edificações típicas da geometria urbana e a redução da captação do calor latente devido à baixa quantidade de água nos materiais urbanos (Oke, 1987).

As médias da TE de janeiro e fevereiro de 2016, às 18:00, apresentaram as mesmas condições térmicas que os dois meses anteriores. Porém, no mês de janeiro os horários de 6:00, 12:00 e 18:00 mostraram as mesmas sensações térmicas em quase todas as ciclovias e ciclofaixas, com pequenas diferenças. Dentre elas, podemos destacar o conforto térmico às 6:00 nas ciclofaixas de $\mathrm{Eng}^{\circ}$ do Meio e parte da ciclofaixa de San Martin, ocorrendo uma sensação de calor moderado na mesma região.

No mês de fevereiro, às 18:00, todas as ciclofaixas forneciam ao ciclista uma sensação levemente quente para as suas atividades. É válido ressaltar que nos demais horários, fevereiro apresentou a mesma configuração espacial em toda malha cicloviária de Recife. Diante desses desconfortos térmicos para os ciclistas, alguns estudos mostram a eficiência de determinados produtos para amenizar a sensação térmica de calor. Podemos exemplificar a utilização do Mentol-Spray na pele dos ciclistas com o intuito de proporcionar um maior frescor e, consequentemente, maior conforto térmico. O seu uso prolongou a sensação de bem-estar, aumentando o desempenho dos ciclistas (Barwood et al.,2015). Fazendo uma análise comparativa das médias mensais do TE nos três horários, percebese que a sensação térmica nas ciclofaixas e ciclovias variam de acordo com a hora, mês e localização geográfica dessas vias. 
Revista Brasileira de Geografia Física v.12, n.06 (2019) 2313-2324.

OUTUBRO

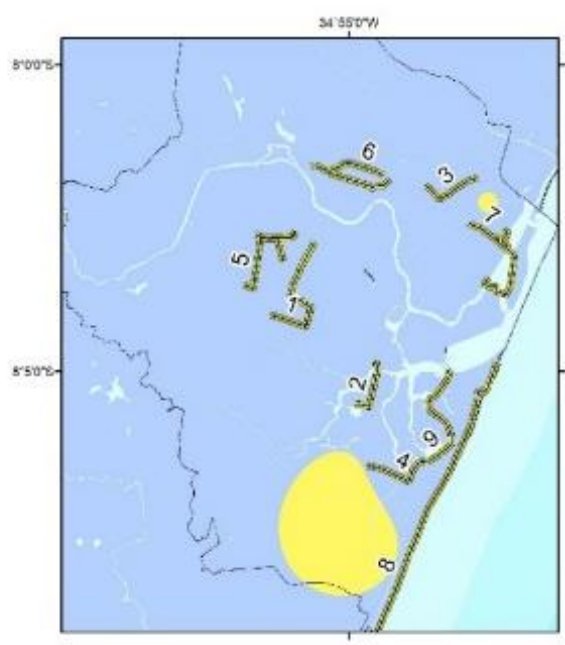

DEZEMBRO

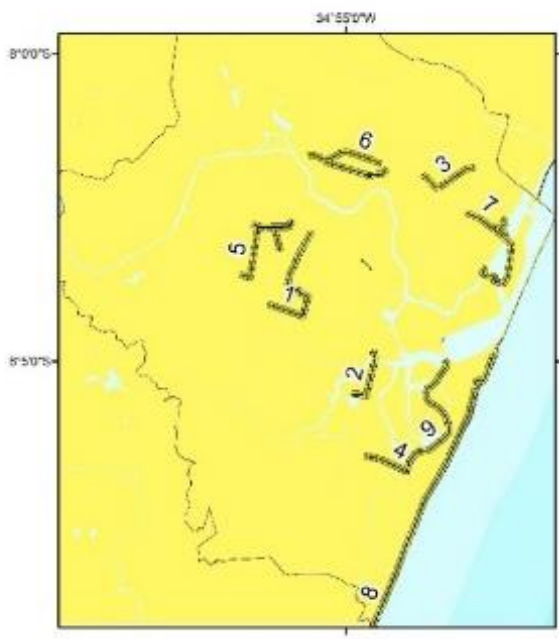

FEVEREIRO

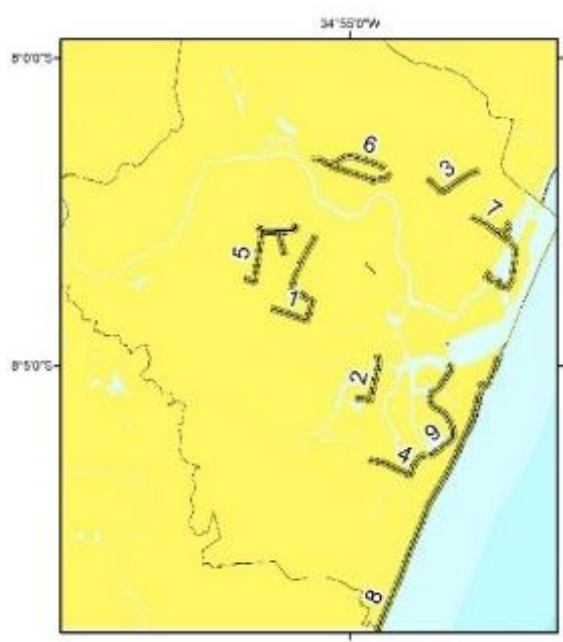

NOVEMBRO

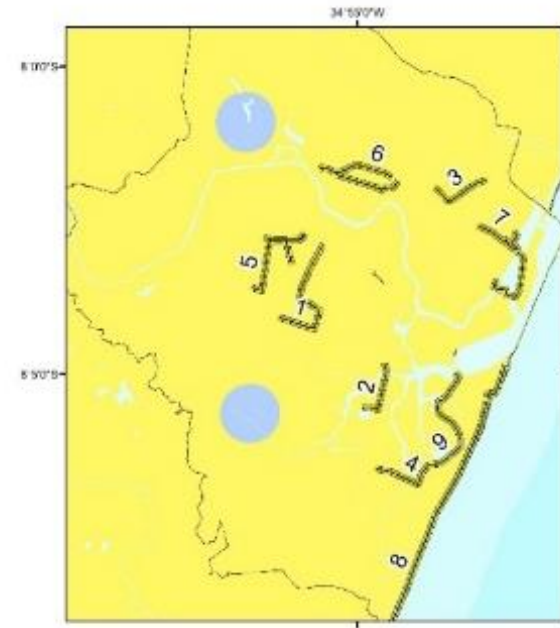

JANEIRO

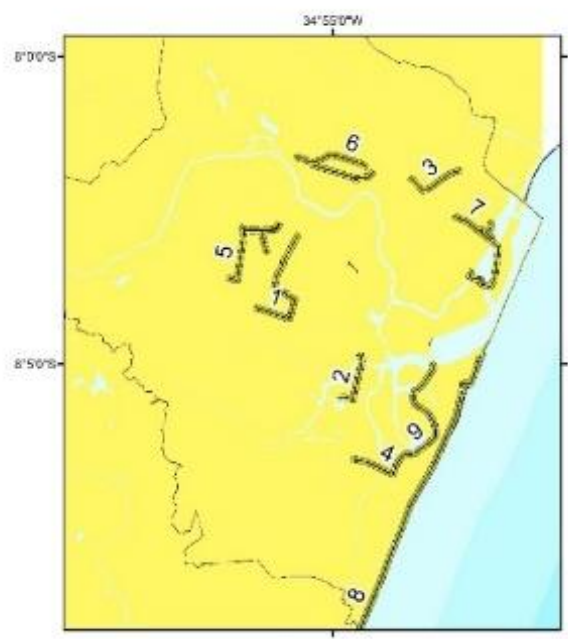

SENSACĀO TÉRMICA E GRAU DE ESTRESSE FISIOLÓGICO

23 - 25 ( Confortável - Neutralidade Térmica)

25 - 28 (Levemente quente - Leve suor e vasodilataçăo)

28 - 31 (Quente moderado - Suando)

\section{MALHA CICLOVIÁRIA}

Ciclofaixa 1 - (San Martin)

Ciclofaixa 2 - (Afogados)

Ciclofaixa 3- (Encruzilhada)

Ciclofaixa 4 - (Imbiribeira)

Ciclofaixa 5 - $\left(\mathrm{Eng}^{\circ}\right.$ do Meio $)$

Ciclofaixa 6 - (Casa Amarela)

Ciclofaixa/Ciclovia 7 - (Bairro do Recife)

Ciclovia 8 - (Boa Viagem)

Ciclovia 9 - (Pina)

\section{CONVENÇŌES CARTOGRÁFICAS}

MASSA D'AGUA

$\square$ LIMITE MUNICIPAL

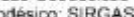

Figura 7. Médias mensais (de outubro de 2015 a fevereiro de 2016), às 18:00, da Temperatura Efetiva associada a sensação térmica, grau de estresse fisiológico e malha cicloviária no município de Recife. 
Revista Brasileira de Geografia Física v.12, n.06 (2019) 2313-2324.

Nesse sentido, deve-se promover ações de planejamento urbano que favoreça condições térmicas confortáveis para os ciclistas, como maior presença de vegetação (favorecendo o aparecimento de sombras), utilização de materiais para a construção das vias com maior albedo (menor absorção de calor) e com a distribuição espacial das edificações que promovam a circulação natural dos ventos. Além disso, sabe-se que a utilização de certos materiais para os ciclistas pode promover sensações térmicas mais agradáveis como a ingestão de líquido com temperaturas amenas, aplicação na pele de Mentol-Spray e roupas adequadas que impeçam a absorção de radiação solar, são alguns dos exemplos.

\section{Considerações finais}

A sensação térmica nas ciclofaixas e ciclovias em Recife-PE variaram de acordo com a hora, mês e localização geográfica. O período que apresentou as melhores condições para pedalar em toda a malha cicloviária foi em outubro de 2015, às 6:00 da manhã. O período que apresentou as piores sensações térmicas de maior calor foi em janeiro de 2016, às 12:00. Contudo, apenas alguns trechos das ciclofaixas e ciclovias foram atingidos pela região de calor moderado (sul do trecho de Boa Viagem e oeste da ciclofaixa do $\mathrm{Eng}^{\mathrm{o}}$ do Meio), estando as demais inseridas na região levemente quente.

Nos três horários analisados, as áreas de calor leve foram as que mais predominaram ao longo de toda a malha cicloviária. No entanto, as regiões de conforto térmico - quando se faziam presentes - predominavam nas ciclofaixas que estavam situadas ao oeste do município, coincidindo com as áreas com maior presença de vegetação.

Apesar da ausência de radiação solar às 18:00, todas as ciclofaixas e ciclovias de Recife, de novembro de 2015 a fevereiro de 2016, apresentaram condições de calor leve para os ciclistas. Alguns fatores podem ser levantados como a absorção de calor das edificações, diminuição do calor latente dos materiais urbanos devido à ausência de água.

O mês de janeiro e fevereiro de 2016 apresentaram condições de sensação de calor na malha cicloviária em todos os horários analisados (6:00, 12:00 e 18:00).

Sugere-se, a partir dos resultados expostos, um planejamento urbano que inclua o conforto térmico ao longo de toda a malha cicloviária, promovendo a saúde para os ciclistas. Além disso, é válido ressaltar os cuidados necessários para os ciclistas em condições térmicas adversas, como a hidratação, evitando as regiões e as horas que possam colocar em risco o bom funcionamento fisiológico do corpo humano.

\section{Agradecimentos}

Os autores agradecem à Fundação de Amparo à Ciência e Tecnologia do Estado de Pernambuco (FACEPE) pelo financiamento a pesquisa.

\section{Referências}

Ayoade, J. O., 2010. Introdução à climatologia para os trópicos. 14 ${ }^{\mathrm{a}}$ ed. Rio de Janeiro: Bertrand Brasil,. 350 p.

Barros, H. R.; Lombardo, M. A., 2012. A relação entre ilhas de calor urbana, ocupação do solo e morfologia urbana na cidade do Recife. Revista Geonorte, Edição Especial 2, 65 - 76.

Barwood, M. J.; Corbet, J.; Thomas, K.; Twentyman, P., 2015. Relieving thermal discomfort: Effects of sprayed L-menthol on perception, performance, and time trial cycling in the heat. Scandinavian Journal of Medicine Science Sports 25, 211-218.

Deval, J. C., 1984, Le confort thermique en climate temperé. Revue Phys. Appl. 19, 513- 531.

Dwyer, D. B., 2014. The effect of environmental conditions on performance in timed cycling events. J Sci Cycling 3, 17-22.

Garcia, L. P.; Rolim, L. R. S.; Duarte, E. C., 2013. Mortalidade de ciclistas no Brasil: características e tendências no período 2000 2010. Rev. Bras. Epidemiologia 16, 918-29.

IBGE. Cidades. Disponível em <http://cidades.ibge.gov.br/xtras/perfil.php? lang $=\&$ codmun $=261160 \&$ search $=$ pernambuco recife|infograficos:-informacoes-completas> . Acesso em agosto de 2017.

INSERM., 2008. Activité physique, contextes et effets sur la santé. Les édition Inserm, Paris.

Melo, V. A., 2010. Por uma história do conceito esporte diálogos com Reinhart Koselleck. Rev. Bras. Cienc. Esporte, Campinas, 32, 41-57.

Melo, R. J. E. S., 2009. Desportos de Natureza: reflexões sobre a sua defnição conceptual. Revista Exedra, no 2, p. 93 - 104.

Melo, V. A.; Schetino, A., 2009. A bicicleta, o ciclismo e as mulheres na transição dos séculos XIX e XX. Estudos Feministas 17, 296.

Moreira, E. B. M.; Galvíncio, J. D. Análise multitemporal da ilha de calor urbana na cidade do Recife, através de imagens do Landsat TM5., 2009. Anais XIV Simpósio Brasileiro Remoto, Natal, Brasil, INPE, 1441-1448. 
Revista Brasileira de Geografia Física v.12, n.06 (2019) 2313-2324.

Nóbrega, R. S.; Vital, L. A. B., 2010. Influência da Urbanização sobre Microclima de Recife e Formação de Ilha de Calor. Revista Brasileira de Geografia Física 03, 151- 156.

Oke, T.R., 1987. Boundary layer climates. $-2^{\text {nd }} \mathrm{ed}$. Londres: Menthuen e Co, 272-302.

Palotta, M.; Herdies, D. L.; Gonçalves, L. G. G., 2015. Estudo das condições de tempo e conforto térmico no desempenho esportivo aplicado à maratona da cidade do Rio de Janeiro. Revista Brasileira de Meteorologia, v.30, n.2, 223 - 240.

Prefeitura Do Recife. Relatório da Malha Cicloviária existente da cidade. Disponível em $<$ http://www2.recife.pe.gov.br/sites/default/file s/relatorio_malha_ cicloviaria_ atual.pdf $>$. Acesso em agosto de 2017.

Prefeitura Do Recife. Rotas cicláveis. Disponível em < http://www2.recife .pe.gov.br /servico/rotas-ciclaveis?op=NTI1NQ> . Acesso em agosto de 2017.

Schulzen, E.; Daanen, H A. M.; Plews, D. J.; Siegel, R.; Laursen, P., 2015. Effect of Thermal State and Thermal Comfort on Cycling Performance in the Heat. Journal International Journal of Sports Physiology and Performance. 1-24. 